\title{
CLINICO - EPIDEMIOLOGICAL TREND OF SPUTUM POSITIVE PULMONARY TUBERCULOSIS IN PATIENT ATTENDING TERTIARY CARE HOSPITAL AT GARHWAL - UTTARAKHAND
}

Dr. Deependra Kumar Rai, Dr. Amit Kumar Singh.

1. Assistant Professor, Department of TB \& Chest,VCSGGMSRI-Srinagar, Garhwal (Uttarakhand)

2. Associate Professor, Department of Community Medicine, -Srinagar, Garhwal (Uttarakhand)

\section{CORRESPONDING AUTHOR}

Dr. Amit Kumar Singh,

Associate Professor, Community Medicine,

VCSGGMSRI - Srinagar

Garhwal (Uttarakhand)

E-mail: Singh120377@yahoo.co.in,

Ph: 919410392588.

ABSTRACT:BACKGROUND \& OBJECTIVE: The present study was undertaken to know the epidemiological trend of sputum positive Pulmonary Tuberculosis in Garhwal region of Uttarakhand which may be useful for programme planners to plan the resource requirement and for monitoring the RNTCP. MATERIAL \& METHOD: Socio demographic profiles of all patients coming to medical OPD between Jan 2008 to Dec. 2011 with cough more than three weeks and from Oct 2010 Patients with cough for more than 2 weeks were recorded. Data from DOTS centre and medical OPD were collected and trend as well as proportion of sputum positive PTB (pulmonary Tuberculosis) in patients coming from different districts of Garhwal region coming to Tertiary care hospital was studied. RESULT: The proportion of sputum positive pulmonary tuberculosis in tertiary care hospital was six cases per thousand in adult patients in 2008, in next three year it was 4 cases per thousand. The sputum positivity in pulmonary suspect varies from $11.91 \%$ (2010) to $14.06 \%$ (2008). If we compare district wise, sputum positivity was maximum in patients coming from Tehri district $(14.37 \%)$ and least in Pauri $(12.50 \%)$ district. The number of PTB suspect required for detection of each sputum positive pulmonary tuberculosis patients was 7.10 in 2008, 8.18 in 2009, 8.36 in 2010 and 7.36 in 2012. CONCLUSION: The proportion of sputum positive PTB was high in patients coming from Garhwal region of Uttarakhand .The sputum positivity rate and number of Pulmonary Tuberculosis suspect required for detection of one sputum positive Pulmonary tuberculosis in patients coming from different district of Garhwali varies in different district in different year.

KEYWORDS: TB, Tuberculosis, PTB. Pulmonary Tuberculosis, DOTS. Directly observed treatment short course, RNTCP, Revised National Tuberculosis Control Programme

INTRODUCTION: Tuberculosis, an infection caused by Mycobacterium Tuberculosis is a worldwide pandemic and the Centre for Disease Control and Prevention (CDC) state that onethird of the world's population is infected with the bacteria. India, with its population of over 1000 million is estimated to account for nearly 30 per cent of the global tuberculosis burden. ${ }^{1}$ Tuberculosis (TB) continues to be a major health problem in India because of its high mortality and morbidity. ${ }^{2}$ Data on the burden of tuberculosis are vital for programme planners in order to calculate the resource requirements and monitor the nation-wide TB control programme. The National Tuberculosis Control Programme (NTP) was implemented in 1962. However when 
reviewed in 1992, after three decades of implementation the NTP was shown to have made no epidemiological impact, mainly due to poor case finding and low treatment completion rates ${ }^{3}$. As a result, the Government of India (GOI) in 1993 developed the Revised National Tuberculosis Control Programme (RNTCP) based on the internationally recommended Directly Observed Treatment - Short course (DOTS) strategy. Since 1998, the RNTCP has undergone a rapid expansion, and by November 2004 covered a population of over 920 million. ${ }^{4}$ Based on the findings of the National Sample Survey (NSS) conducted by Indian Council of Medical Research (ICMR) during 1955-58, ${ }^{5}$ an estimate of the burden of TB in India of 3.5 million bacillary cases and 14 million persons with abnormal chest X-rays suggestive of tuberculosis with negative sputum (hereafter, referred to as X-ray abnormal) was made at the time of introduction of RNTCP in 1997. 6 The nationwide survey by Indian Council of Medical Research in the late 50's (1955-58) had shown an average prevalence of sputum positive pulmonary tuberculosis of about 400 per 100,000 populations amounting to an absolute number of 1.5 million infectious cases at that time with similar prevalence rates in rural and urban areas. ${ }^{7}$ Unfortunately, we do not have the latest nation-wide data after this report nearly 50 years ago although scattered confined regional data is available off and on. Disease surveys conducted in different parts of the country since the 1950s have reported prevalence of smear-positive pulmonary TB (PTB) of 0.6-7.6 per 1000 population, culture-positive TB of 1.7-9.8 and culture and/or smear-positive TB of 1.8 - 12.7. The incidence of smear-positive PTB has been observed in the range of 1.01.6/1000 and that of culture-positive PTB 1.0-2.5/1000 in the limited number of studies carried out.

Indian population is composed of people of diverse cultural, linguistic, biological, ethnic and genetic backgrounds, living in different socio-cultural and socio-economic settings.

The present study was conducted to estimate prevalence and socio - demographic trend of sputum positive Pulmonary Tuberculosis in patients coming to HNB base hospital in last four years.

MATERIALS \& METHODS: Study Area The study was conducted in Chest \& TB department of VCSG Government medical college, Srinagar - Garhwal, Uttarakhand situated in mid Himalayan region of Uttarakhand. This medical college drains patients mainly from districts of Garhwal like Pauri, Rudraprayag, Chamoli and Tehri.

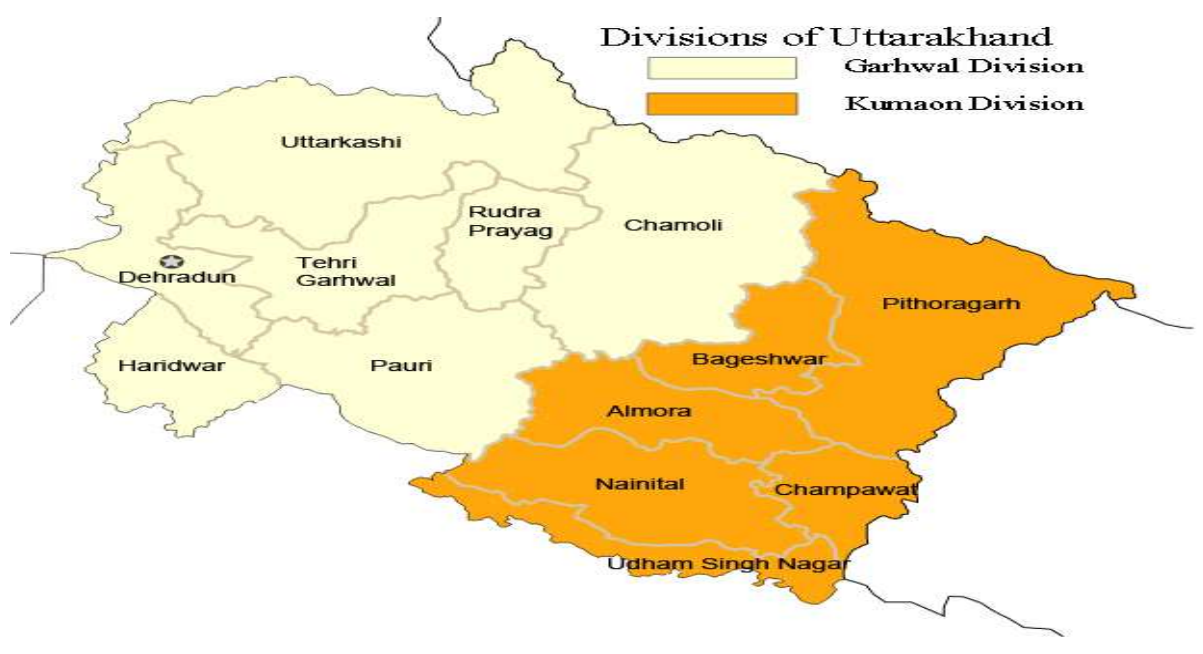

Journal of Evolution of Medical and Dental Sciences/Volume1/ Issue4/Oct-Dec 2012 Page 292 
Study design \& Data collection

Type of Study: Hospital record based study.

Study Period: The study was conducted by analysing the data from Jan 2008 to Dec. 2011.

METHOD: Standard RNTCP diagnostic algorithm includes all patients coming in medical OPD between Jan 2008 to Dec. 2011 with cough with more than three weeks and from Oct 2010 Patients with cough for more than Two weeks. Information on patients' socio-demographic characteristics, cough duration in days or weeks and sputum results were studied. The proportion, Sputum positivity in Pulmonary TB suspect and socio demographic trend of Patients coming from four district of Garhwal was analysed.

OPERATIONAL DEFINITIONS: A PTB suspect: All patient attending medical OPD with history of cough for three weeks (from Oct 2010, two weeks) or more.

SPUTUM POSITIVE PTB: Patients with at-least two sputum specimens positive for acid -fast bacilli (from Oct 2010 at least one sputum specimen positive for acid-fast bacilli by microscopy)

ETHICAL CONSIDERATIONS: Permission was sought from Principal/Dean of the institute to carry out the present study. Data analysis has been done using SPSS version 15.0 and Microsoft Office Excel 2007.

RESULT:

Table 1 Total suspect case in four districts in different years

\begin{tabular}{|c|c|c|c|c|c|c|c|c|c|}
\hline \multirow{2}{*}{ Year } & \multicolumn{2}{|c|}{ Pauri } & \multicolumn{2}{c|}{ Rudraprayag } & \multicolumn{2}{c|}{ Chamoli } & \multicolumn{2}{c|}{ Tehri } & \multirow{2}{*}{ Total } \\
\cline { 2 - 10 } & Suspects & $\mathbf{\%}$ & Suspects & $\mathbf{\%}$ & Suspects & $\mathbf{\%}$ & Suspects & $\mathbf{\%}$ & \\
\hline $\mathbf{2 0 0 8}$ & 285 & 18.86 & 355 & 23.65 & 368 & 22.77 & 300 & 23.06 & $\mathbf{1 3 0 8}$ \\
\hline $\mathbf{2 0 0 9}$ & 433 & 28.66 & 381 & 25.38 & 429 & 26.55 & 365 & 28.06 & $\mathbf{1 6 0 8}$ \\
\hline $\mathbf{2 0 1 0}$ & 379 & 25.08 & 372 & 24.78 & 468 & 28.96 & 346 & 26.59 & $\mathbf{1 5 6 5}$ \\
\hline $\mathbf{2 0 1 1}$ & 414 & 27.4 & 393 & 26.18 & 351 & 21.72 & 290 & 22.29 & $\mathbf{1 4 4 8}$ \\
\hline Total & $\mathbf{1 5 1 1}$ & & $\mathbf{1 5 0 1}$ & & $\mathbf{1 6 1 6}$ & & $\mathbf{1 3 0 1}$ & & $\mathbf{5 9 2 9}$ \\
\hline
\end{tabular}

Table 2 Total sputum positive pulmonary TB cases

\begin{tabular}{|c|c|c|c|}
\hline Year & Total Suspects & Total[+ve] & $\begin{array}{c}\text { Total[- } \\
\text { ve] }\end{array}$ \\
\hline 2008 & 1308 & 184 & 1124 \\
\hline 2009 & 1608 & 204 & 1404 \\
\hline 2010 & 1565 & 187 & 1378 \\
\hline 2011 & 1448 & 197 & 1251 \\
\hline Total & 5929 & 772 & 5157 \\
\hline
\end{tabular}

Chi-square: 3.447 , The $P$ value is 0.3276 .

Chi-squared for trend $=0.2318$ ( 1 degree of freedom). The $P$ value is 0.6302 .

There is no significant linear trend of Tuberculosis cases in the population. 
Table 3.Sputum positivity in different years

\begin{tabular}{|c|r|r|r|}
\hline Year & $\begin{array}{c}\text { Total PTB } \\
\text { suspects }\end{array}$ & $\begin{array}{c}\text { Total } \\
\text { sputum } \\
\text { positive } \\
\text { cases }\end{array}$ & $\begin{array}{c}\text { Sputum } \\
\text { positivity } \\
\mathbf{( \% )}\end{array}$ \\
\hline $\mathbf{2 0 0 8}$ & 1308 & 184 & 14.07 \\
\hline $\mathbf{2 0 0 9}$ & 1608 & 204 & 12.69 \\
\hline $\mathbf{2 0 1 0}$ & 1565 & 187 & 11.95 \\
\hline $\mathbf{2 0 1 1}$ & 1448 & 197 & 13.60 \\
\hline Total & $\mathbf{5 9 2 9}$ & $\mathbf{7 7 2}$ & $\mathbf{1 3 . 0 2}$ \\
\hline
\end{tabular}

Sputum positivity in pulmonary TB suspect varies from $11.91 \%$ to $14.06 \%$

Table 4 Sputum positivity in different district

\begin{tabular}{|l|c|c|c|c|}
\hline \multicolumn{1}{|c|}{ District } & Total suspect & $\begin{array}{c}\text { Total sputum } \\
\text { positive cases }\end{array}$ & $\begin{array}{c}\text { Sputum } \\
\text { positivity } \\
\text { rate }\end{array}$ & $\begin{array}{c}\text { Number of suspect } \\
\text { required for each } \\
\text { sputum positive } \\
\text { cases }\end{array}$ \\
\hline Pauri & 1511 & 189 & 12.5 & 7.99 \\
\hline Rudraprayag & 1501 & 200 & 13.32 & 7.5 \\
\hline Chamoli & 1616 & 196 & 12.12 & 8.24 \\
\hline Tehri & 1301 & 187 & 14.37 & 6.95 \\
\hline Total & $\mathbf{5 9 2 9}$ & $\mathbf{7 7 2}$ & & \\
\hline
\end{tabular}

Table 5.Proportion of sputum positive pulmonary tuberculosis in different quarter

\begin{tabular}{|c|c|c|c|c|c|}
\hline Year & $\mathbf{1}^{\text {st }} \mathbf{Q}$ & $\mathbf{2}^{\text {nd }} \mathbf{Q}$ & $\mathbf{3}^{\text {rd }} \mathbf{Q}$ & $\mathbf{4}^{\text {th }} \mathbf{Q}$ & Total \\
\hline $\mathbf{2 0 0 8}$ & 49 & 56 & 44 & 35 & $\mathbf{1 8 4}$ \\
\hline $\mathbf{2 0 0 9}$ & 49 & 75 & 43 & 37 & $\mathbf{2 0 4}$ \\
\hline $\mathbf{2 0 1 0}$ & 47 & 50 & 40 & 50 & $\mathbf{1 8 7}$ \\
\hline $\mathbf{2 0 1 1}$ & 42 & 67 & 55 & 33 & $\mathbf{1 9 7}$ \\
\hline Total & $\mathbf{1 8 7}$ & $\mathbf{2 4 8}$ & $\mathbf{1 8 2}$ & $\mathbf{1 5 5}$ & $\mathbf{7 7 2}$ \\
\hline
\end{tabular}

Table 6. Age and sex wise distribution of sputum positive Pulmonary TB cases

\begin{tabular}{|c|c|c|c|c|c|c|c|c|c|c|}
\hline \multirow{2}{*}{ Year } & \multicolumn{2}{|c|}{ 0 - 19} & \multicolumn{2}{|c|}{$20-39$} & \multicolumn{2}{|c|}{$40-59$} & \multicolumn{2}{|c|}{$>60$} & \multicolumn{2}{|c|}{ Total } \\
\hline & $\mathbf{M}$ & $\mathbf{F}$ & $\mathbf{M}$ & $\mathbf{F}$ & $\mathbf{M}$ & $\mathbf{F}$ & $\mathbf{M}$ & $\mathbf{F}$ & $\mathbf{M}$ & $\mathbf{F}$ \\
\hline 2008 & 5 & 6 & 51 & 26 & 47 & 11 & 34 & 4 & 137 & 47 \\
\hline 2009 & 5 & 10 & 61 & 26 & 48 & 8 & 37 & 9 & 151 & 53 \\
\hline 2010 & 9 & 8 & 58 & 21 & 49 & 10 & 26 & 6 & 142 & 45 \\
\hline 2011 & 12 & 8 & 61 & 23 & 49 & 10 & 31 & 3 & 153 & 44 \\
\hline Total & 31 & 32 & 231 & 96 & 193 & 39 & 128 & 22 & 583 & 189 \\
\hline
\end{tabular}

Chi-square: 42.997 , The $\mathrm{P}$ value is $<0.0001$. The age and sex are significantly associated. 
Table 7. Proportion of sputum positive pulmonary TB cases in Tertiary care hospital of Garhwal in different yrs. (2008 - 2011)

\begin{tabular}{|c|c|c|c|c|}
\hline Year & $\begin{array}{c}\text { Total OPD } \\
\text { patients }\end{array}$ & $\begin{array}{c}\text { Total } \\
\text { Pulmonary } \\
\text { suspect }\end{array}$ & $\begin{array}{c}\text { Total sputum } \\
\text { positive PTB }\end{array}$ & $\begin{array}{c}\text { Proportion of sputum } \\
\text { positive pulmonary } \\
\text { Tuberculosis in base } \\
\text { hospital }\end{array}$ \\
\hline $\mathbf{2 0 0 8}$ & 30428 & $1308(4.29 \%)$ & 184 & 6 cases $/ 1000$ \\
\hline $\mathbf{2 0 0 9}$ & 40037 & $1608(4.02 \%)$ & 204 & 4 cases $/ 1000$ \\
\hline $\mathbf{2 0 1 0}$ & 44372 & $1565(3.52 \%)$ & 187 & 4 cases $/ 1000$ \\
\hline $\mathbf{2 0 1 1}$ & 42402 & $1448(3.41 \%)$ & 197 & 4 cases $/ 1000$ \\
\hline Total & $\mathbf{1 5 7 2 3 9}$ & $\mathbf{5 9 2 9}(\mathbf{3 . 7 7 \%})$ & $\mathbf{7 7 2}$ & \\
\hline
\end{tabular}

Table 8. Sputum positive pulmonary Tuberculosis cases and suspects (2008 -2011)

$\begin{array}{ccc}\text { Year } & \begin{array}{c}\text { Total sputum positive } \\ \text { PTB }\end{array} & \begin{array}{c}\text { Number of suspect for } \\ \text { each sputum positive } \\ \text { cases }\end{array} \\ \mathbf{2 0 0 8} & 184 & 9.16 \\ \mathbf{2 0 0 9} & 204 & 10.15 \\ \mathbf{2 0 1 0} & 187 & 9.30 \\ \mathbf{2 0 1 1} & 197 & 9.80 \\ \text { Total } & \mathbf{7 7 2} & \mathbf{1 3 . 0 2}\end{array}$

A total number of 5929 patient which is equivalent to $3.75 \%$ of new adult OPD patient between 2008 to 2011 were referred for sputum microscopy in DOTS centre, 762 pts were sputum positive giving sputum positivity rate of $12.89 \%$ The proportion of sputum positive pulmonary tuberculosis in tertiary care hospital was six cases per thousand adult OPD patient in 2008, in next three years it was 4 cases per thousand adult OPD per year. The sputum positivity in pulmonary suspect varies from $11.91 \%$ (2010) to $14.06 \%$ (2008). If we compare district wise, sputum positivity was maximum in patient coming from Tehri district( $14.37 \%$ ) and least in Pauri (12.50\%). The maximum number of sputum positive pulmonary Tuberculosis was found in $2^{\text {nd }}$ Quarter in comparison to other quarter. The proportion of sputum positive pulmonary Tuberculosis and sputum positivity was highest in 20 to 40 years age group. The number of sputum positive Pulmonary Tuberculosis was three times more common in male compares to female. The number of pulmonary tuberculosis suspect required for detection of each sputum positive Pulmonary Tuberculosis patients was 7.10 in 2008, 8.18 in 2009, 8.36 in 2010 and 7.36 in 2012. If we compare the number of suspect required for detection of one sputum positive pulmonary Tuberculosis case in patients coming from different district were 7.99 for pauri district and 7.50, 8.24, 6.95 for Rudraprayag, Chamoli and Tehri respectively.

DISCUSSION: The proportion of Sputum positive Pulmonary Tuberculosis in patients coming to chest and medical OPD was varies from 4-6 cases per 1000 OPD patients which was similar to 
prevalence of Sputum positive pulmonary tuberculosis in India. 8 There is no precise information on case detection rate from Garhwal region of Uttarakhand. Our finding suggests that sputum positive pulmonary tuberculosis was more in male than female patients except in patient between 0-19 years where ratio between male and female were almost equal this finding was similar to previous studies. ${ }^{9}$ The proportion of sputum positive PTB were almost equal between male and female patients in 0-19 age group this was a different finding in compare to other study. The reason for this is not known, but one study interprets that women have inability to produce good and quality sputum. ${ }^{10}$ Nevertheless this indicates that expanding TB case detection activities to maternal and child health clinics, antenatal and family planning clinics may lead to detection of more females suspects. In this study highest burden of sputum positive pulmonary Tuberculosis and maximum sputum positivity rate was found in productive age group which is similar to earlier studies. ${ }^{11}$ In our study number of TB suspect from elderly group were as high as in productive age group but sputum positivity rate were very low and this may be due to inadequate, poor quality sputum production and number of other causes of sputum production like chronic bronchitis etc. ${ }^{12}$ The number of TB suspect examined for each sputum positive case in patients coming from Garhwal region were high in 2009 and 2010 but again in 2011 less number of suspect were examined for detection of each sputum positive cases and this may suggest underperformances of the national Programme. There was an average of 7 to 8 suspect required for each sputum positive cases. The number of suspect require for detection of one sputum positive PTB was also influenced by change in Pulmonary Tuberculosis suspect definition, change in case definition and number of sputum positive Pulmonary tuberculosis .There was also an observation that number of suspect require for detection of one sputum positive case was maximum in patients coming from Chamoli district in compare to other district like Rudraprayag, Tehri and Pauri.

CONCLUSION: The highest burden of sputum positive pulmonary Tuberculosis and maximum sputum positivity rate was found in productive age group. The proportion of sputum positive PTB was more in male than female patients. All age group except in patient between 0-19 year's ratio between male and female were almost equal. The number of suspect required for detection of one sputum positive PTB was also influenced by change in PTB suspect definition and number of sputum positive PTB. In this study number of suspect required for detection of one sputum positive pulmonary tuberculosis was maximum for Chamoli district in compare to other districts of Garhwal .

\section{REFERENCES:}

1. Dye C, Scheele S, Dolin P, Pathania V, Raviglione MC. Consensus statement. Global burden of tuberculosis: estimated incidence, prevalence, and mortality by country. WHO Global Surveillance and Monitoring Project. JAMA 1999; 282 : 67786.

2. Murray CJL, Lopez AD, editors. The global burden of disease. Cambridge: The Harvard School of Public Health; 1996 p. 660. 3. World Health Organization. Tuberculosis Programme Review - India. 1992. Geneva: WHO; 1992.

3. TB India 2005. RNTCP Status Report.Central TB Division, Directorate of General of Health Services, Ministry of Health and family Welfare, New Delhi. http:// www.tbcindia.org.

4. Tuberculosis in India (special report series No. 34). A Sample Survey 1955-58; Indian Council of Medical Research, New Delhi. 
5. Kant L. On estimation of burden of tuberculosis in India (Editorial).Indian J Tuberc2000; $47: 127-8$.

6. Tuberculosis in India (special report series No.34). A sample Survey 1955-58; Indian Council of Medical Research, New Delhi

7. 8.ChadhaVK.Epidemiological situation of tuberculosis in India. Journal of the Indian Medical Association2003; 101: 144-147.

8. 9.World Health Organization: Global Tuberculosis Control: Sur-veillance, Planning, financing. WHO report. Geneva2007

9. 10.13Murthy KRJ, Yazdani A, Lakshmi KA: Use of oral salbutamol in improving quality sputum microscopy in the DOTS strategy. Int J Tuberc Lung Dis2000, 4(12):1191-1192

10. 11.Godo y P, Dominguez A, Alcaide J, Camps N, Jansa J, Minguell SM et al. Patients belief regarding tuberculosis \& its outcome. European Journa 1 of public health.2001; 14(10): 71-75.

11. 12.Nagami P, Yoshikawa TT. Tuberculosis in the geriatric patient. J Am

12. Geriatr Soc1983; 31:356-63. 